\title{
Article \\ A System Dynamic Model for Sustainable Ecotourism in Tasik Kenyir, Terengganu, Malaysia
}

\author{
Muhamad Safiih Lola ${ }^{1,2, *}$, Mohd Fadli Hussin ${ }^{3, *}$, Izham Mohamad Yusoff ${ }^{3}$, \\ Mohd Noor Afiq Ramlee ${ }^{1}$, Siti Hanani Isa ${ }^{4}$, Anton Abdulbasah Kamil ${ }^{2}$, Nur Zafirah A. Khadar ${ }^{2}$ \\ and Mohd Tajuddin Abdullah ${ }^{2}$ \\ 1 School of Informatics and Applied Mathematics, Universiti Malaysia Terengganu, 21300 Kuala Terengganu, \\ Terengganu, Malaysia; afiqramlee91@gmail.com \\ 2 Kenyir Research Institute, Universiti Malaysia Terengganu, 21300 Kuala Terengganu, Terengganu, \\ Malaysia; anton@usm.my (A.A.K.); zafirah1987@gmail.com (N.Z.A.K.); \\ mohd.tajuddin@umt.edu.my (M.T.A.) \\ 3 School of Distance Education, Universiti Sains Malaysia, 11800 Pulau Pinang, Malaysia; izham@usm.my \\ 4 Institute of Biotechnology Marine, Universiti Malaysia Terengganu, 21300 Kuala Terengganu, Terengganu, \\ Malaysia; hananiisa85@yahoo.com.my \\ * Correspondence: safiihmd@umt.edu.my (M.S.L.); mohdfadlihussin@gmail.com (M.F.H.); \\ Tel.: +6-09-668-3247 (M.S.L.)
}

\begin{abstract}
The sustainability of ecotourism is the backbone of tourism development of a country. Ecotourism can contribute to both conservation and development in which involves dynamic relationship between tourism, biodiversity and communities, facilitate by great management. The purpose of this study is to analyze the dimensions of the socio-economic and environmental impacts of ecotourism in communities surrounding the Tasik Kenyir in Terengganu, Malaysia. This study provides a framework for the development and evaluation of ecotourism. The framework will determine if the relationships between indicators are positively correlated which will result in positive contribution to the other by using System Dynamic. Socio-cultural and economic data will be collected through interviews and group discussions in selected communities in Tasik Kenyir. Data on wildlife will be extracted from secondary data from Kenyir Research Institute, Universiti Malaysia Terengganu. The data analysis will explore the socio-cultural and economic differences between and within different communities due to ecotourism development, the contribution of ecotourism to conservation activities, local support for conservation and ecotourism as well as the influence of tourist activities on the distribution of wildlife species in Tasik Kenyir. This study aims to contribute toward understanding the natural resource community-ecotourism inter-relationship and help to bridge the knowledge gap that hinders biodiversity conservation initiatives. The findings will be used as a base for further development of ecotourism and will recommend alternative management options where necessary for the study area.
\end{abstract}

Keywords: sustainability; ecotourism; System Dynamic; tourism; biodiversity; communities

\section{Introduction}

Ecotourism has been widely recognized as a form of nature tourism which is expected to contribute to both conservation and development [1]. The word ecotourism come from two terms which are "eco" and "tourism". "Eco" bring two logical meaning, "ecology and economy" which are to show that it is possible to make "good tourism" and reconcile the imperatives of ecology and economy [2]. In Malaysia, this industry will generate the economic which is estimated around MYR72.0 billion in revenue in 2014 [3], which means 1.47\%t from the total world revenue. With that figures, eco-tourism is a real industry that seeks to take advantage of market trends. This is the main reason why many developing countries are now embracing it and including in their economic 
development and conservation strategies [4]. Besides that, eco-tourism's perceived potential as an effective tool for sustainable development.

Sustainable ecotourism is crucial part for sustainable development which is capable of generating income, provide job opportunities and protect local biodiversity [5]. Besides, sustainable ecotourism also able to meet the need of economic, social and local biodiversity. In addition, sustainable ecotourism uses the resources of an area and attempts to create a balance between potential and existing activities. Equity, justice, poverty alleviations, and local community empowerment are also related to sustainability [6].

The global growth of tourism poses a significant threat to cultural and biological diversity. Hence the needs of sustainable tourism that applied in conserving and conservation niche are in a great demand for parks and nature tourism. 'Sustainable tourism' has become one of the keywords in the debate on environmentally integrated tourism development, largely a result of the insight that the environmental consequences of this rapidly growing industry can no longer be ignored [7]. To incorporated scientific value in tourism niche in Malaysia, an understanding of behavior and complex system of tourism itself need to be understood. To come out with this, System Dynamics was introduce to cater certain information based on real time analysis. System Dynamic is a system that analyses behavior of complex systems over time. It deals with internal feedback loops and time delays that affect the behavior of the entire system. Hence, this particular system helps to describe a non-liner events and dynamic changes that occurs from certain events that's need to be hold [8].

On this paper, we shall discuss the sustainable ecotourism in an exotic and rich tourism spot which located in Terengganu, Malaysia. Terengganu holds the charms and splendor from others state in Malaysia. Despite rapid development and modernization, it is as if time has stood still as the state retains all the rustic and idyllic charms so different from other tourist destination. The abundance of costal area with pearly white beach and breath taking island promote Terengganu to be one of the most popular island related tourism activity. But, despite of revisiting tourists towards the sandy beach and island, in monsoon seasons that start from early November to mid-February, all activity related towards the sea are ceased functioning for a while, this produce an income gap towards tourism activity in Terengganu [1]. But, many did not know that Terengganu still offer a unique gateway such as Tasik Kenyir and other attractive places to be explore.

Ever since early 1980, environmentalist had prioritized eco-tourism as an aspect of leaving green for the future. For years of researching of ways to boosts economic value of tourism and producing sustainable ecosystems for future, several agency as UNESCO and plenty of researcher have put up their mind in order to come out with a plan for it [9].

As eco-tourism seem uniting two goals of ecological conservation and economic development and successful eco-tourism requires maximizing its environmental and economic benefits while minimizing ecological damage, unfortunately all the eco-tourism projects are not completely successful in attaining their objectives [10,11]. Environmental deterioration and inequitable development, many a times has been found as ill impacts of eco- tourism [12]. This research explain that how eco-tourism is boosting conservation. But at the same time it will also explain that how eco-tourism is a potential threat to local community and ecosystem along with the suggestions regarding careful planning for eco-tourism [13]. The definition of eco-tourism are viewed it as a two ways of shifting experience and understanding behavior. A model of shifting series of indicators witch use to measure the transitions that been suggested has been come out [14]. A system dynamics has been utilized to examine development of tourism in Kenya. As they finds that development there resulting series of negative impacts, they suggest that system dynamics must be used to provide insights and balancing between negative and positive impacts for this kind of tourism development [15]. A research on how to stimulate both surrounding industry and tourism has been 
conducted for they may growth collaborate in order to create sustainable tourism activity and promote economic growth [16].

In the field of sustainable development, a research using SD method to provide an experimental simulation platform for the long-term environmental sustainability analysis of the interconnected strategic problems in their interconnected context. They examined how environmental policy affects the investment and development decisions of the mining industry within the context of sustainable development, through quantitative analysis of existing data, using system dynamics model [17]. In addition, a system dynamic models has been constructed by including five subsystem which are population, economy, housing, transport and developed land, on the sustainable land use and urban development in Hong Kong which is used to test the outcomes of development policy scenarios and make forecast [18]. As for now, system dynamics prove to be useful to provide information and analysis and could be used to produce models for sustainable tourism and eco-tourism framework for future use especially in Tasik Kenyir, Terengganu, Malaysia.

Tasik Kenyir is the biggest man-made lake in Southeast Asia. Tasik Kenyir consist of abundance of natural wonders and rich in biodiversity. As shown in Figure 1, Tasik Kenyir covered by more than 340 islands spread out in water catchments area of 38000 hectares. The biggest island would be estimated as big as Singapore. And Tasik Kenyir got her name from one of the river known as Kenyir River but now the river is beneath the lake when Tasik Kenyir almost filled by the rainfall and surrounding water sources. With over 30 rivers runs in and out, this lake also consists of 25 waterfalls and approximately 300 species of fresh fishes [18]. Dotted with more than 340 islands throughout the lake, which were once mountaintops and highlands, Lake Kenyir is home to more than 14 cascading waterfalls, cooling waters, an abundance of rapids and rivers, and an idyllic sanctuary to numerous species of freshwater fish and exotic wildlife [19].

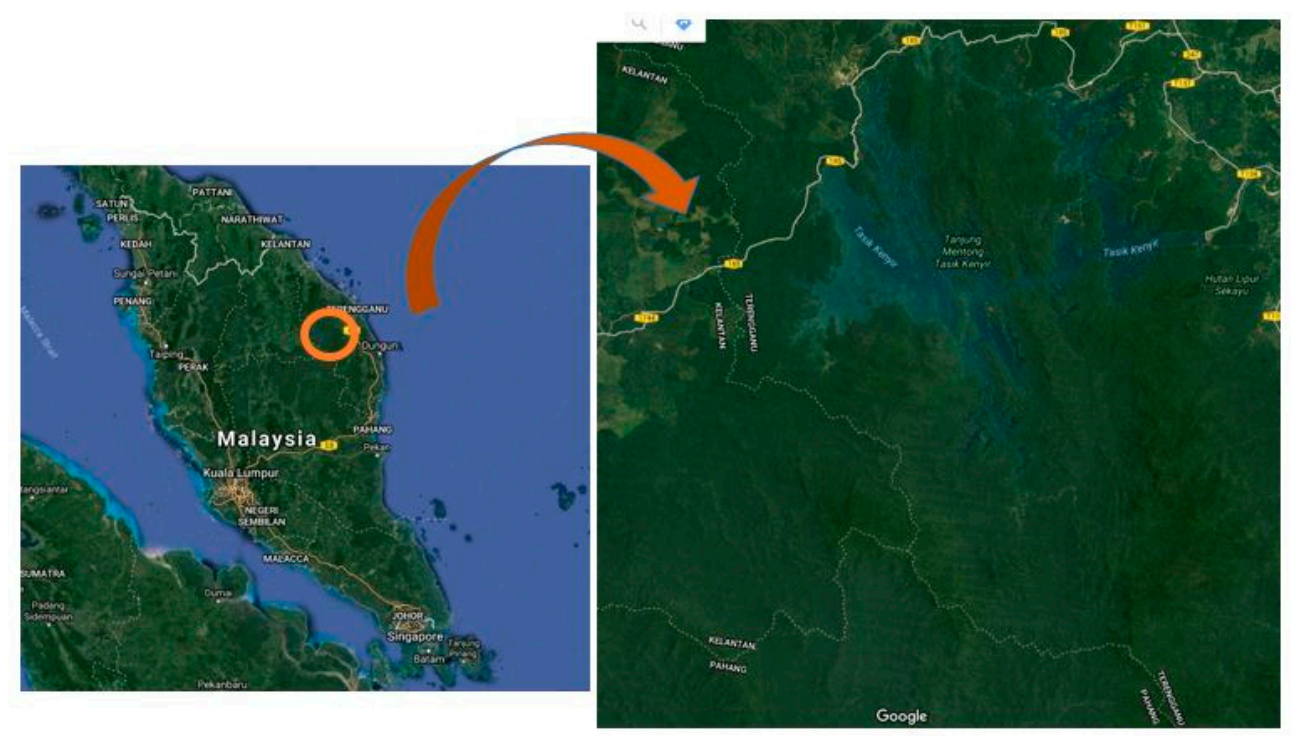

FIGURE 1: Location Map of Lake Kenyir

Lake Kenyir was placed under supervision of Terengganu Tengah Development Authorities or known as KETENGAH. The Terengganu Tengah Development Authority (KETENGAH), an agency under the Ministry of Rural and Regional Development, was incorporated on 12 April 1973 by Parliament Act No. 104/73 with authorization to carry out economic and social development in an area of 443.876 hectares covering the interior of Dungun, Kemaman and Hulu Terengganu Districts. On 12 June 1993, the Lake Kenyir Development area in Hulu Terengganu covering 209,199 hectares was gazette via LN (B) 356 with area gazette plan No. PW486 as part of KETENGAH, making the KETENGAH region a total of 653,075 hectares or about one-half the size of Terengganu state $[18,19]$. 
Massive projects and development at Tasik Kenyir are in progress recently. Some are good, but other seems to be out of the supposedly Kenyir's "bigger picture". In terms of enhance and highlight 130 million years of rich history and diversity of Kenyir, sustainable tourism development should take places there. As recent data show in a fair amount increase of tourism activities in Kenyir [3], it was feared that Lake Kenyir should have its own planning in balancing its ecosystem value, economic development, and community engagement. Hence, with this particular planning, it was hope that it could increase this rate of visitor and submerge into travois sustainable development in the future without losing its heritage value [20]. Based on data provided in Table 2, we quote the number of tourist in Tasik Kenyir based on data provided from KETENGAH for past 5 years from 2008 till 2012.

TABLE 2: Number of Tourist in Tasik Kenyir ('000)

\begin{tabular}{clllll}
\hline Year & $\mathbf{2 0 0 9}$ & $\mathbf{2 0 0 9}$ & $\mathbf{2 0 1 0}$ & $\mathbf{2 0 1 1}$ & $\mathbf{2 0 1 2}$ \\
\hline Tourist in Kenyir & 133 & 189 & 225 & 275 & 269 \\
\hline
\end{tabular}

\section{Materials and Methods}

\subsection{Method}

\subsubsection{System Dynamic}

System dynamic (SD) developed by Professor Forrester from MIT in mid-1950s was applied in several of research field. SD is a methodology and computer simulation modelling technique for framing, understanding and discussing of a system with complex issues and problems. This particular research method was chosen because system dynamics was widely used for economic, social and environmental studies as result as this particular method proven useful to reveal the dynamic changes, feedback and other variable cause and effect onto its particular area. By utilizing this particular method in research, we could provide insights for positive and negative effect that been derived from artificial model based on actual surrounding environment [21].

Basically the typical purpose of a SD study on sustainability issues is to simulate complex interrelationship between sustainability variables and seek appropriate quantitative solutions to measure environmental, economic and social responses in the whole system. SD model is more beneficial to explain the developing trends of dynamic behaviors in the long-term due to its feedback structure and capability to function under different parameter settings and initial inputs. In addition, SD model also could assist decision makers with the simulation results to develop sustainability policies [22-24].

There are three general steps in developing system dynamics model as shown in Figure 2. These steps will be used in order to analyze the dimensions of the socio-economic and environmental impacts of ecotourism in communities surrounding the Tasik Kenyir in Terengganu, Malaysia. The step started with problem description which involves the process of understanding the problem, system characteristics is deepened, also impacts on social, economy and biodiversity are recognized. Then, development of dynamic hypothesis consists of building a causal loop diagram shows the causality between the factors that had been recognized. Lastly, the process ended with developing a system dynamic model through computer simulation [25]. 
Figure 2: The process of system dynamic model development

\subsection{Materials}

\subsubsection{Problem Description}

In this research, system dynamic is used to study the relationship of eco-based tourism development in Tasik Kenyir and tourist arrival, and does eco-based tourism produce sustainability in economic, community and ecology development in Tasik Kenyir. Furthermore, system dynamic is used to identify the relationship between tourism based development and geo-heritage value in Tasik Kenyir. In addition, system dynamic also used to study the complex inter-relation between eco-tourism and financial benefits and empower of indigenous people and does eco-tourism raise awareness to socio-political issues in Tasik Kenyir. Therefore, the sustainable management of ecotourism in Kenyir is focus on a dynamic interaction between community, biodiversity and tourism. The study applies a framework (Figure 3) which considers ecotourism in term of synergistic links and uses indicators to determine if the existing relationships are operating in a way to allow each to make positive contribution to the other [1]. One of the purposes of this study is to analyze the dimensions of the socio-economic and environmental impacts of ecotourism in communities surrounding the Tasik Kenyir. This will result on a new policy introduced by the policy-maker as a new benchmark. Therefore, we built system dynamics model called as "Sustainable Management of Ecotourism - System Dynamics" or "SMEc-SD" based on ecotourism interrelationships.

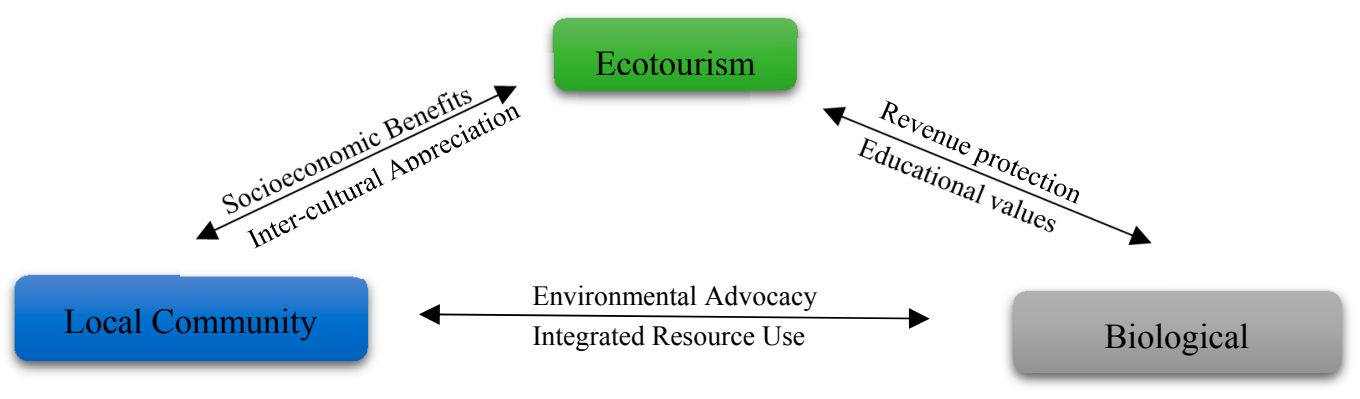

Figure 3: A conceptual framework for SMEc-SD

\subsubsection{Dynamic Hypothesis}

In this research, a few interview session are conducted to gain information about the dimension of the impact of ecotourism towards local community, tourism sector and biological diversity. In addition, a set of questionnaire are distributed among tourist to gain information about their willingness to pay for conservation, satisfaction toward facilities and tourism activity offered by Tasik Kenyir and do they plan to revisit to Tasik Kenyir or not. After that, few visits were conducted to feels and gain an experience as a tourist and to observe the environment in Tasik Kenyir including the facilities, services provided by employee and the tourism activities. Further on, causal loop diagram is used to analyze the dimension of the impact of ecotourism in Tasik Kenyir. 
The SD modelling approach uses causal-loop diagram to show a system's feedback structure. A causal-loop shows cause-effect relations among system variables and enlighten a dynamic process of a system in which the chain effects of a cause are traced, through a set of related variables, back to the original cause. A causal loop is formed when a set of variables has been linked together in a connected path. Cause-effect variable pairs positively related are represented by a plus sign added to the link; otherwise, a minus sign results. A positive-feedback loop could trigger an embedded system variable growth process over time while a negative-feedback seeks a goal and responds through achieving a stable state $[21,26]$. Causal loop also represent by an arrow headed line with a symbol " + " mean a change in the influencing variable will produce a change of the same direction in the target variable while the symbol "-" mean the effect will in a opposite direction between the influencing variable and the target variable. The causal loops relation is a helpful tool to predict the impact of desired factors in the system holistically [21,26,27].

According to the framework (Figure 3), the casual loop diagram of the SMEc-SD model is designed and displayed on Figure 4. The central node, which is Sustainable management strategies, links with all key elements in the system and generates several loops.

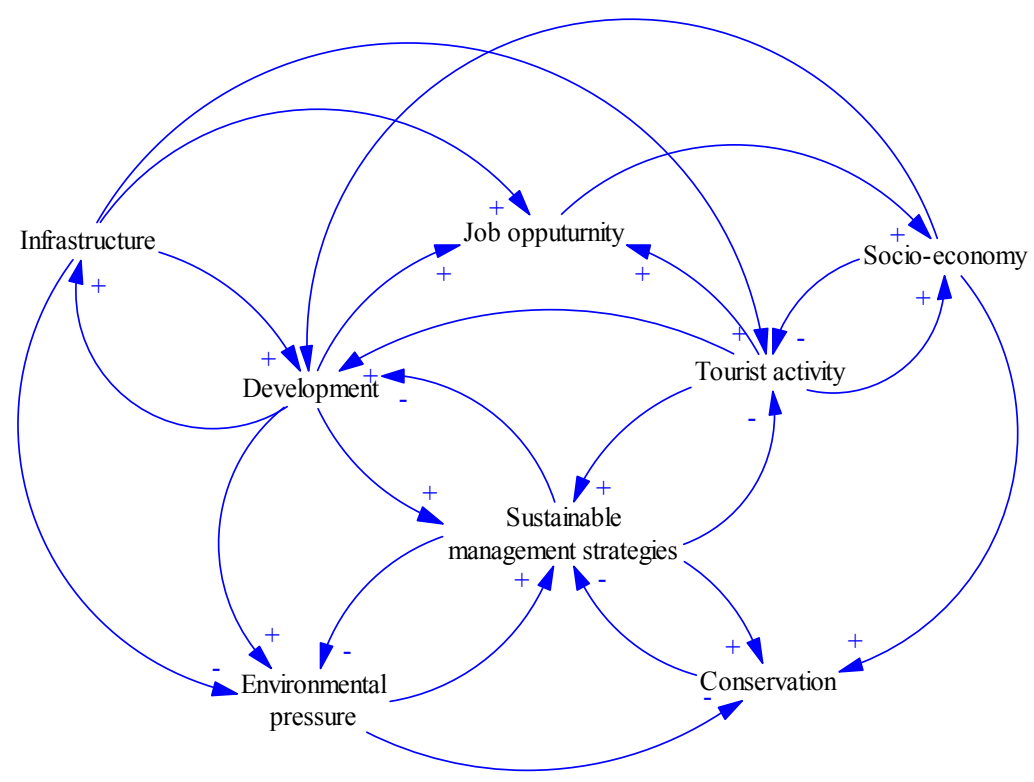

Figure 4: The causal loop diagram of SMEc-SD model.

Figure 4 shows a causal loop diagram of SMEc-SD model which central node of sustainable management strategies and end with environmental pressure and tourist activities. There are positive and negative feedback loop which describe three subsystem of the dimension of the impact of sustainable ecotourism towards social, economy and biodiversity in Tasik Kenyir.

\subsubsection{Development of System Dynamic Model}

In this research, all factors presented in Figure 4 were transformed into stock and flow diagrams (Figure 6) by using Vensim software to build the system dynamics model of "Sustainable Management of Ecotourism - System Dynamics" or "SMEc-SD". The development of system dynamics model includes several types of variables such as stocks, flows, converters and connectors. The SMEc-SD model contains 3 main impact which are toward the social, economy and biodiversity.

i. Stock-flow Diagram 
Stock which is also known as levels act as a reservoir to accumulate quantities (represented by rectangle) and describe the condition of the system as described in Figure 5. The flows increasing (inflow) and decreasing (outflow) a stock are also known as rates (represented by valve). The condition of stock will depend on the rates while the rates can be affected by a factor affecting inflow or outflow which is known as converter or auxiliaries (represented by circle). Finally, the connectors represent cause and effect links within the model structure is represented by the single-line arrow [3].

Stock-flow diagram is the core of SMEc-SD model, and is the process of quantization and materialization of causal loop diagram by using Vensim software. Based on stock-flow Figure 5, the related mathematical equation in the mathematical model of system dynamics can be shown in Equation 1.

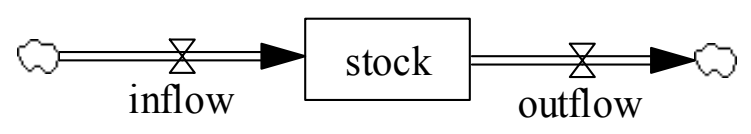

FIGURE 5: Basic stock-flow diagram for SD.

$$
\frac{d x}{d t}=x=\text { netflow }=\text { Inflow }- \text { Outflow }
$$

From Equation 1, $x$ is referred as a Stock and $\frac{d x}{d t}$ comes from $\frac{\Delta x}{\Delta t}$ where $\Delta x$ is a change in $x$ and $\Delta t$ is a change in $t$ [28]. In this study, the differential equations built by stock flow diagram, the whole ecotourism system is stimulated quantitatively and dynamically using Vensim software format as Figure 6.

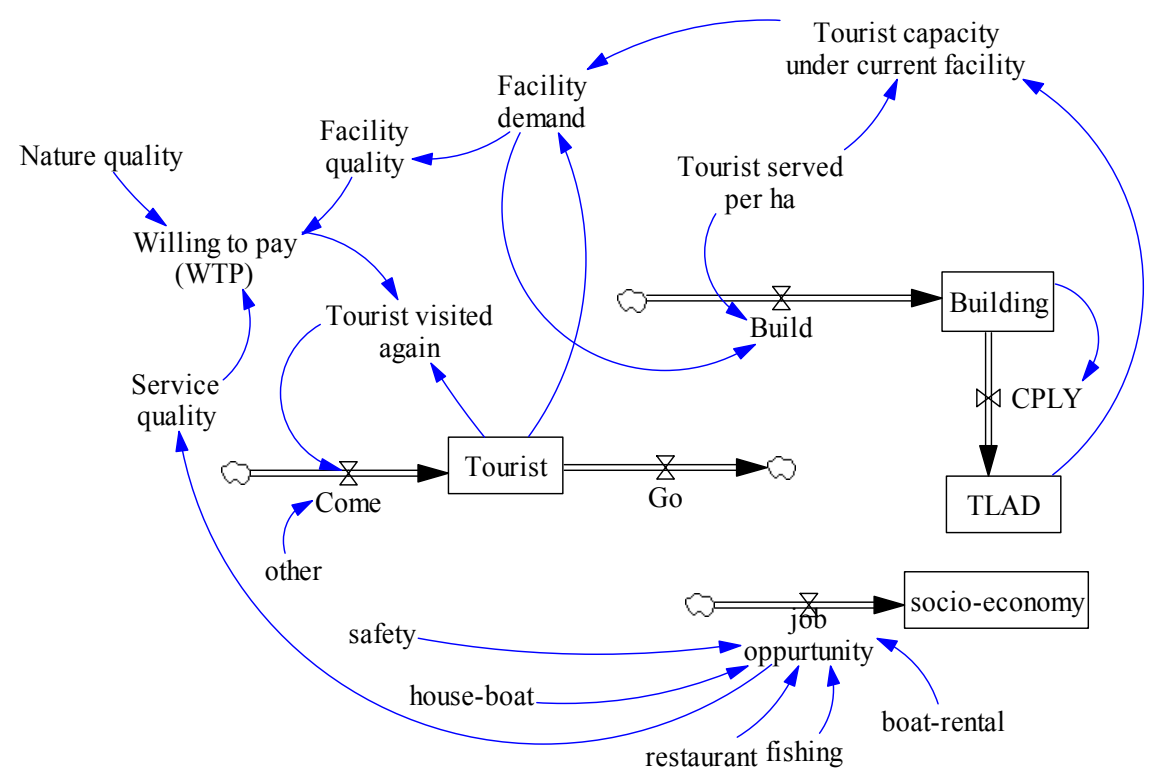

Figure 6: Stock-flow diagram for ecotourism in Tasik Kenyir 
Fig. 6 is the stock-flow diagram of the socio economic subsystem which represents critical socio-economic factor interactions such as tourist activities and land developments. The willing to pay (WTP) index, showing whether tourist will visit again and serves as the bridge for connecting the key factors in all subsystems. WTP represents the tourist degree of attraction and can relates to the tourist population [10]. The variable WTP links two key elements in the system, which are the land area under construction and the accumulated tourist number, each represented by the stock variables BUILDING and TOURIST respectively. WTP model is formulated according to tourist travel experiences using key parameters of facility quality (FQ), nature quality (NQ), and service quality (SQ) as shown in Equation 2 [16].

$$
W T P=S Q \times N Q \times F Q
$$

FQ is affected by facility demand (FD) that is the deviation of TOURIST and F_TC, tourist capacity sustained by current facilities. The value of tourist capacity under current facilities (F_TC) can be find by multiplying (A_COTS), constant tourist number served per hectare (ha) by (TLAD), total land development area as shown in Equation 3.

$$
F_{-} T C=A_{-} C O T S \times T L A D
$$

The stock variable TLAD accumulates the land area under construction from the stock variable BUILDING, and thus the linkage between WTP and BUILDING is identifiable. BUILIDING varies depending on two flow rate variables, which are monthly land area under construction (BUILD) and monthly land area finishing construction (CPLY).

On the other hand, WTP links with number of tourist visited again (NTVA). A higher WTP value suggests more tourists will come back due to good traveling experience. Furthermore, the socio-economic subsystem has strong connections with the environmental and ecological subsystems to address the integration issue as required by the complex sustainable ecotourism management problem.

\section{Results}

Ecotourism will not be successful without effective management [24]. The management subsystem enables users to perform scenario analysis in which system variables and managerial planning relations are adjusted according to designated strategies. Decision makers in this way, can evaluate diverse strategies and provide strong decision support functionalities. Four major management strategies cover land development, protected area, entrance fees and wastewater treatment. Land development limitation could overcome the threat of reduction of species and the loss of habitats in Tasik Kenyir. Protected areas are very important to ensure the quality of the available natural experiences.

\subsubsection{The willing to pay (WTP) index}

Figure 7 shows a simulation result on WTP among tourist in Tasik Kenyir. Based on the result, WTP index proved that the number of tourist that willing to pay for revisit Tasik Kenyir is increasing from time to time. As WTP serves as the bridge for connecting the key factors in all subsystems, it may affect other parameter. Figure 7 clearly shows that as the number of tourist are willing to pay (WTP) increasing, it shows that more tourist are willing to pay for sustainability development in Tasik Kenyir. WTP is influenced by the nature quality, services quality and facilities quality. 


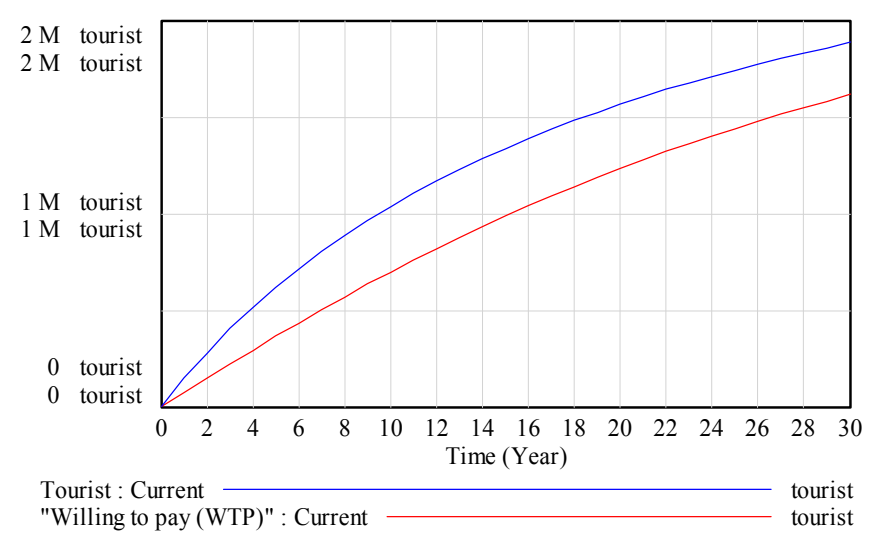

Figure 7: The willing to pay (WTP) in Tasik Kenyir

\subsubsection{Tourist Capacity}

The value of tourist capacity under current facilities (F_TC) increase rapidly (Figure 8). It shows that as a total land development area increasing, the tourist number served per hectare will also increasing. For example, as a water theme park in Kenyir was fully developed, it may increase the tourist capacity in Kenyir. At the beginning, Tasik Kenyir is focus on the nature experience for nature lover which is majority are adult. And most of them did not bring their children due to challenging activity promoted by Tasik Kenyir and only suitable for an adult. Today, tourist are able to bring their children to Tasik Kenyir because there is other attraction which is suitable for children in Tasik Kenyir. This scenario will also increase the number of tourist in Tasik Kenyir.

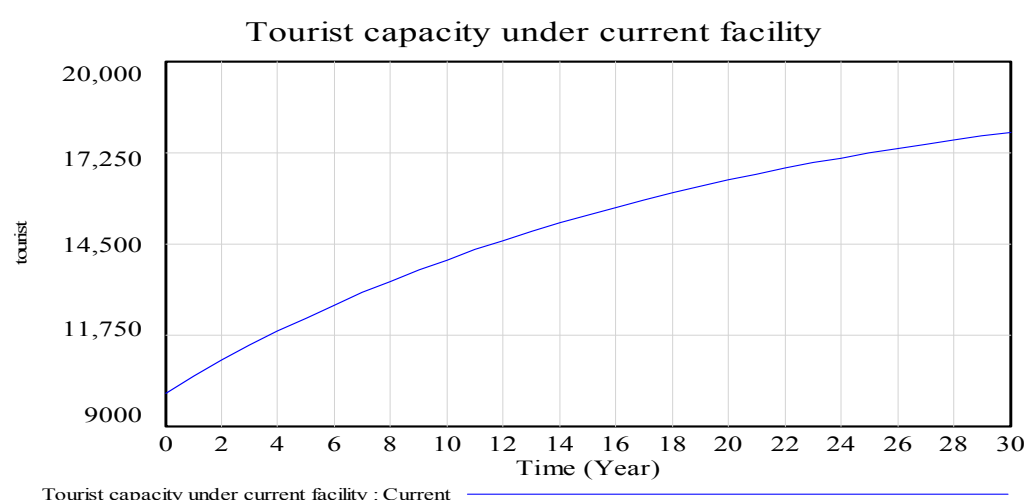

Figure 8: The value of tourist capacity under current facilities (F_TC)

\subsubsection{Socio-economy}

As tourism activity become more popular in Tasik Kenyir, the number of tourist visit to Tasik Kenyir become higher. But, there has been an increase in conflict between the locals and the tourism activity. This is due to the fact that the people in the areas have not derived meaningful benefits. The simulation result in Figure 9 shows that the socio-economy among local people is also increasing as the tourism activity increasing. It shows that the net benefit of tourism accruing to the local people. 
Tourism activity in Tasik Kenyir offers plenty job opportunities among local people. They can work in forestry, hospitality, restaurant, houseboat, security, tourist guide and much more. Thus, it is clearly shows that the ecotourism in Tasik Kenyir can give a positive impact for the local community.

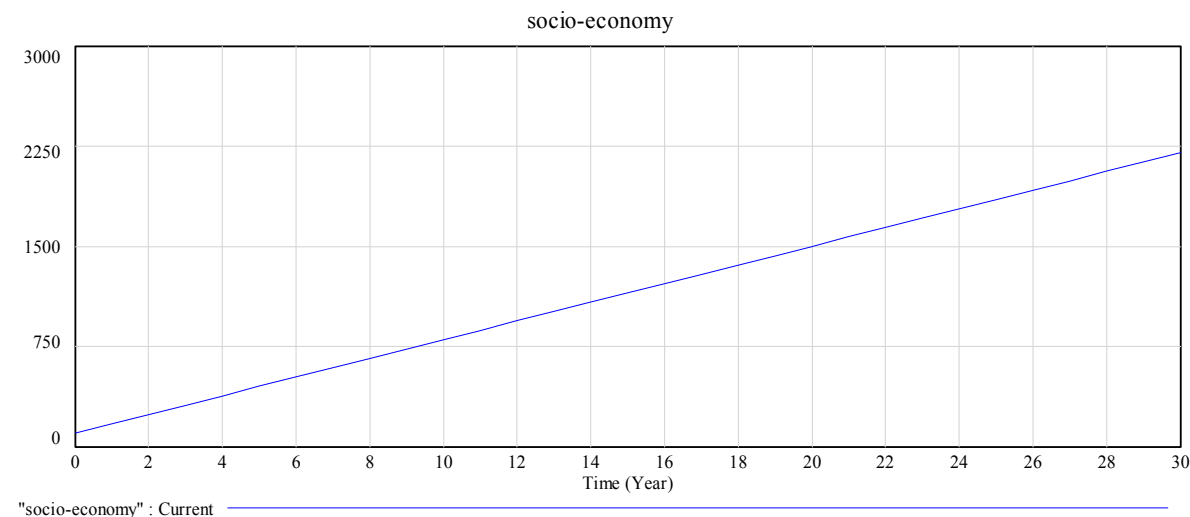

Figure 9: Socio-economy in Tasik Kenyir

\section{Discussion}

\subsection{Improvement Policy Using SMEc-SD}

SMEc-SD allow users to evaluate the system performance based on the future trends of the corresponding simulation for the next 30 years. The current study considered only human-induced disturbances which would affect nature quality. Thus, tourism industry in Kenyir will also affected. Critical parameters related to managerial strategies in the current study are identified as land development and entrance fee collection. The first illustrates stock variable status in socio-economic and ecological subsystem, included accumulated tourist in last 30 years (TOURIST), land development pressure mainly from construction (BUILDING).

\subsubsection{Model structure assessment test (zero action)}

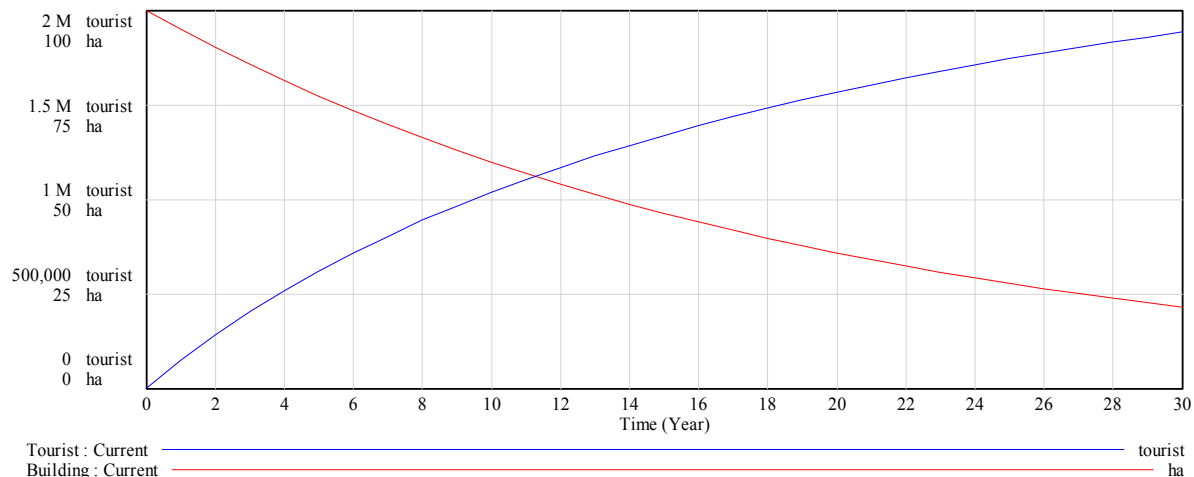

Figure 10: System performances under "zero-action" scenario 
Based on Figure 10, the proposed SMEc-SD model is not for quantification, but it is for demonstrate a complex system to show a reasonable long-term trend. In this case, the zero action scenario was configured to examine whether simulated results preserved ecological system relations. Zero action assumes that no additional management strategies are adopted. The simulation shows that the number of tourist is expected to increase steadily from time to time until it reach at the peak. Even the simulation shows that the number of tourist increases but still it may fail to maintain the nature quality. The main reason of tourist will visit Kenyir may not because of the nature quality anymore but because of other factor that is under development like water theme park and free duty for shopping in Kenyir which is now still under development.

\subsubsection{Improvement policy for ecotourism under "no construction" scenario}

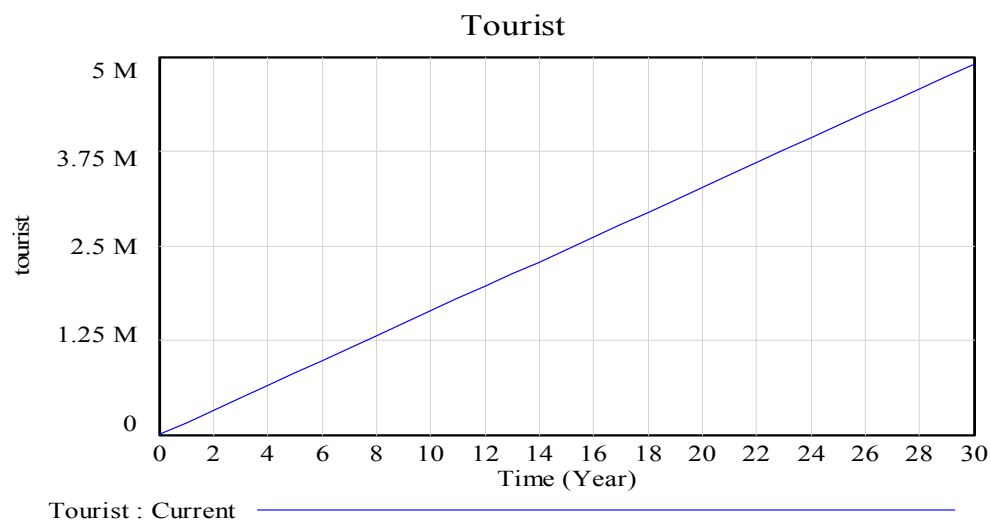

Figure 11: System performances under "no construction" scenario

To maintain the main attraction of Tasik Kenyir which is all about the power of nature, this paper suggest to bans all land development in Tasik Kenyir. As a land for development is continuously develop, it may affect the nature quality in Kenyir such as water quality. Thus, the simulation with no construction shows that the number of tourist are forecast to increase rapidly for the next 30 years. The simulation result as Figure 11 clearly shows that the main attraction among tourist in Tasik Kenyir is the nature itself. Without construction, tourist are able to embrace the beautiful nature scenery with variety of flora and fauna species found in Tasik Kenyir. Without further development, Tasik Kenyir is still have a great attraction among nature lovers.

\section{Conclusions}

System Dynamics is an effective and useful method for the analysis of complex systems, integrating the subsystems and parts into a whole, which can then be simulated to develop insight into its dynamic behavior. This paper presents, SD-based to implement the concept for sustainable ecotourism management in Kenyir. We build and use a system dynamic model "SMEc-SD" to simulate and analyze ecotourism system case. Based on the simulation result, the potential risk and negative effects of the system are identified, and then the system improvement policies are made and proven that they can indeed eliminate the risks and expand the ecological and economic positive effects. 
Acknowledgments: The authors acknowledge the support of the Universiti Sains Malaysia (USM) under the Research Grant Scheme RUI 2015 - Vot No. 1001/PJJAUH1/8219. Kenyir Research Institute, Universiti Malaysia Terengganu in providing secondary data. We would also like to show our gratitude to Lembaga Kemajuan Terengganu Tengah (KETENGAH), and Ministry of Tourism and Culture Malaysia, Terengganu

Author Contributions: S.L. designed the study and revised the manuscript. F.H and A.R analyzed the data and wrote the manuscript; M.T., A.A. and I.Y. provided good advice throughout the paper; Z.K. and H.I. helped collecting data and did the statistics work.

Conflicts of Interest: The authors declare no conflict of interest.

\section{References}

1. Ross, S., \& Wall, G. (1999). Ecotourism: towards congruence between theory and practice. Tourism management, 20(1), 123-132.

2. Villepontoux, S. (2013, May). Ecotourism, concept and reality. What are perspectives? In "ASSURE 2013" is ASSURING SUSTAINABILITY via University with Research 2013: Towards a sustainable earth system environment in Asia Pacific and beyond.

3. Hassan, D. H. (2012). Services Statistic: Domestic Tourism Survey. Malaysia: Jabatan Perangkaan Malaysia.

4. Kiper, T. (2013). Role of ecotourism in sustainable development. Advances in Landscape Arhitecture, Kiper, licensee InTech.

5. McCool, S. F., \& Moisey, R. N. (Eds.). (2001). Tourism, recreation, and sustainability: Linking culture and the environment. Cabi.

6. Dhanoa, R. Shiv Shakti (2013) Eco - Tourism : Conservation Or Exploitation. International Journal in Multidisciplinary and Academic Research (SSIJMAR) Vol. 2, No. 4, July- August (ISSN 2278 - 5973)

7. Hunter, C., \& Green, H. (1995). Tourism and the environment: A sustainable relationship? Routledge.

8. Sterman, J. D. (1992). System Dynamics Modeling For Project Managment. MA. : System Dynamics Group Sloan, School of Managment, Massachusetts Institute of Technology, Cambridge. Muhanna, E. (2006). Sustainable tourism development and environmental management for developing countries. Problems and Perspectives in Management, 4(2), 14-30.

9. Pedersen, A., \& Larderel, J. A. (2002). Managing Tourism at World Heritage Sites: a Practical Manual for World Heritage Site Managers. Paris, France: UNESCO World Heritage Centre. Retrieved from UNESCO: http://whc.unesco.org/uploads/activities/documents/activity-113-2.pdf

10. Chang, Y. C., Hong, F. W., \& Lee, M. T. (2008). A system dynamic based DSS for sustainable coral reef management in Kenting coastal zone, Taiwan. ecological modelling, 211(1), 153-168.

11. Boo, E. (1993). Ecotourism planning in protected areas. In: K. Lindberg, \& D. Hawkins (Eds.), Ecotourism: A guide for planners and managers. (pp.15-54). North Bennington: The Ecotourism Society.

12. Orams, M. B. (1995). Towards a more desirable form of ecotourism. Tourism management, 16(1), 3-8.

13. Chan, Y.W., 2001. Assessment of ecotourism development in terms of the recretional velue in Kenting National Park. Master thesis. Department of Landscape Architecture, Tunghai University, Taiwan.

14. Wamwara-Mbugua, L. W., \& Kamau, E. M. (2006). A Systems Dynamics View of Tourism Development in Kenya.

15. Jin, M., Luo, Y., Liao, Z., Ren, P., \& Gao, H. (2012). Sustainable Development of Economic Circle in Tourist Destinations Based on System Dynamics. Applied Mathematics \& Information Sciences, 1011-1018.

16. Browne, D., O'Regan, B., \& Moles, R. (2010). Use of multi-criteria decision analysis to explore alternative domestic energy and electricity policy scenarios in an Irish city-region. Energy, 35(2), 518-528.

17. Shen, Q., Chen, Q., Tang, B. S., Yeung, S., Hu, Y., \& Cheung, G. (2009). A system dynamics model for the sustainable land use planning and development. Habitat International, 33(1), 15-25.

18. KETENGAH, A. (2014, Mei 5). Index: Laman Web KETENGAH. Retrieved Mei 7, 2014, from Laman Web Rasmi, Lembaga Kemajuan Terengganu Tengah (KETENGAH): http://www.ketengah.gov.my/

19. Shahrom, F. (2012). Fish Parasite of Lake Kenyir, Peninsular Malaysia. Kuala Terengganu, Terengganu, Malaysia: Penerbit UMT, Universiti Malaysia Terengganu. 
20. Nasser, N. (2003). Planning for urban heritage places: reconciling conservation, tourism, and sustainable development. CPL bibliography, 17(4), 467-479.

21. Forrester, J. W. (1997). Industrial dynamics. Journal of the Operational Research Society, 48(10), 1037-1041.

22. Xu, Z., \& Coors, V. (2012). Combining system dynamics model, GIS and 3D visualization in sustainability assessment of urban residential development. Building and Environment, 47, 272-287.

23. Muhamad Safiih, L, Mohd Noor Afiq, R., Hanani, I., Mhd Ikhwanuddin, A., Mohd Fadli, H., Nurul Hila, Z., and Mohd Naeim, R. (2016). Forecasting towards Planning and Sustaiable Development Based on System Dynamic Approach: A Case Study of the Setiu District, State of Terengganu, Malaysia. Open Journal of Statistics, 6. 931-950.

24. Muhamad Safiih, L, Mohd Noor Afiq, Mohd Naeim, R., Mhd Ikhwanuddin, A., Madzli, H., Syerrina, Z., and Marzuki, I. (2016). A system dynamics model for analyzing the eco-aquaculture system with policy recommendations: Case study on Integrated Aquaculture Park (i-Sharp), Setiu Terengganu, Malaysia. AIP Conference Proceedings of

25. Maani, K.E \& Cavana, R.Y. Systems Thinking and Modeling, Understanding Change and Complexity, Pearson Education N.Z press, 2000, pp. 16-70.

26. Sterman, J. D. (2001). System dynamics modeling: tools for learning in a complex world. California management review, 43(4), 8-25.

27. Coyle, R. G. (1996). System dynamics modelling: a practical approach (Vol. 1). CRC Press.

28. Craig W. Kirkwood (1998). System Dynamics Methods: A Quick Introduction. College of Business Arizona State University, (version 1 \{ 4/1/98)

(C) 2017 by the authors; licensee Preprints, Basel, Switzerland. This article is an open access article distributed under the terms and conditions of the Creative Commons by Attribution (CC-BY) license (http://creativecommons.org/licenses/by/4.0/). 